\title{
The General Factor of Psychopathology
}

\author{
Gregory T. Smith \\ Emily A. Atkinson \\ Heather A. Davis \\ Elizabeth N. Riley \\ Joshua R. Oltmanns \\ University of Kentucky
}

Correspondence concerning this article can be addressed to Gregory T. Smith, gsmith@email.uky.edu, 106 Kastle Hall, Department of Psychology, University of Kentucky, Lexington, KY, 40506 0044. Emily A. Atkinson: Emily.Atkinson@uky.edu; Heather A. Davis: hdavis@uky.edu; Elizabeth N. Riley: enriley1231@gmail.com; Joshua R. Oltmanns: jroltmanns@uky.edu. 


\begin{abstract}
An important advance in understanding and defining mental disorders has been to take empirical approaches to mapping dimensions of dysfunction and their inter-relatedness. Such empirical approaches have consistently observed intercorrelations among the many forms of psychopathology, leading to the identification of a general factor of psychopathology (p). In this article, we review empirical support for $p$, including evidence for the stability and criterion validity of $\mathrm{p}$. Further, we discuss the strong relationship between $\mathrm{p}$ and general factors of personality (GFP) and personality disorders (g-PD), substantive interpretations of $\mathrm{p}$, and the potential clinical utility of $\mathrm{p}$. We posit that proposed substantive interpretations of $\mathrm{p}$ do not explain the full range of symptomatology typically included in $\mathrm{p}$. The most plausible explanation is that $\mathrm{p}$ represents an index of impairment that has the potential to inform the duration and intensity of a client's mental health treatment.
\end{abstract}

Keywords: p factor, bifactor models, comorbidity, psychopathology, impairment, mental health treatment 


\section{CONTENTS}

$\begin{array}{ll}\text { INTRODUCTION } & 4\end{array}$

$\begin{array}{ll}\text { EVIDENCE FOR THE P FACTOR } & 4\end{array}$

$\begin{array}{ll}\text { Structural and criterion validity of } \mathrm{p} & 6\end{array}$

Genetic basis of $\mathrm{p} \quad 9$

$\begin{array}{ll}\text { Stability of p over time } & 10\end{array}$

$\begin{array}{ll}\text { Statistical modeling of p: Implications } & 13\end{array}$

p COMPARED WITH GENERAL FACTORS OF PERSONALITY (GFP) AND 14

PERSONALITY DISORDER (g-PD)

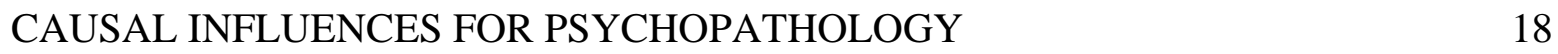

SUBSTANTIVE INTERPRETATIONS OF THE p FACTOR 18

$\begin{array}{ll}\text { Dispositional negative emotionality } & 18\end{array}$

$\begin{array}{ll}\text { Impulsive responsivity to emotion } & 19\end{array}$

$\begin{array}{ll}\text { Low cognitive functioning } & 20\end{array}$

$\begin{array}{ll}\text { Thought dysfunction } & 21\end{array}$

LIMITATIONS OF SUBSTANTIVE INTERPRETATIONS OF THE P FACTOR 21

Impairment as explanation of what p measures $\quad 22$

$\begin{array}{ll}\text { THE CLINICAL UTILITY OF P } & 25\end{array}$

P assessment for treatment planning and establishing treatment goals 27

How to assess p? 31

FUTURE DIRECTIONS 33 


\section{INTRODUCTION}

This paper provides a critical review of the literature on the general factor for psychopathology (the p factor: Caspi et al., 2014; Lahey 2012), including empirical support for the $\mathrm{p}$ factor, evaluation of different interpretations of $\mathrm{p}$, and discussion of its potential clinical utility. We have four primary aims for this paper: First, we define and discuss evidence for the $\mathrm{p}$ factor. We highlight research on the existence of $\mathrm{p}$, discuss findings regarding the criterion validity and stability of $\mathrm{p}$, and discuss the relationship between $\mathrm{p}$ and the general factor of personality (GFP) and general factor of personality disorder (g-PD). Second, we discuss current proposed explanations for the $\mathrm{p}$ factor. Researchers have proposed several competing hypotheses regarding the underlying dimensions which may account for $\mathrm{p}$ : Nonspecific causal factors (Lahey et al., 2017), dispositional negative affectivity (Tackett et al., 2013), impulsive responsivity to emotion (Carver et al., 2017), thought dysfunction (Caspi \& Moffitt 2018), and impairment (Oltmanns et al., 2018; Widiger \& Oltmanns 2017). These hypotheses vary in the degree to which $\mathrm{p}$ is given substantive meaning. Third, we turn to the possible clinical utility of the p-factor. It may be useful to assess $\mathrm{p}$ in addition to assessing the specific disorder for which a person presents for treatment, and assessment of $\mathrm{p}$ may have important implications for treatment modality and prognosis. Fourth, we conclude by reviewing outstanding research questions in this area.

\section{EVIDENCE FOR THE P FACTOR}

Evidence for a $\mathrm{p}$ factor of general psychopathology has emerged, in part, due to an increasing reliance on empirical methods for understanding the dimensional structure of psychopathology. Historically, the definition of mental disorders has been influenced by 
considerations other than empirical data concerning the nature, dimensions, and inter-relatedness of problem behaviors or symptoms (Kotov et al., 2017). A central example of this history is the traditional use of distinct categorical conditions as reflected in versions of the Diagnostic and Statistical Manual of Mental Disorders (DSM). This approach proved to have a number of limitations (see Kotov et al., 2017 for a thorough discussion of this topic). First, traditional systems defined mental disorders as categories. This approach is at odds with a vast body of empirical work providing compelling evidence that psychological dysfunction exists along continua (Kotov et al., 2017; Widiger \& Samuel 2005; Wright et al., 2013). Second, traditional categorical diagnoses tend to have low reliability, whereas dimensional assessments do not (Kotov et al., 2017). Third, many traditional diagnoses are remarkably heterogeneous, such that two individuals can have the same diagnosis with few or no symptoms in common (Widiger \& Trull 2007), thus rendering the meaning of the diagnosis unclear. Fourth, comorbidity among supposedly distinct categorical diagnoses is the norm, rather than the exception (Hasin \& Kilcoyne 2012; Kessler et al., 2005). Fifth, in the absence of clear empirical evidence for the existence of categories of mental dysfunction (such evidence does not exist for any DSM disorder: Kotov et al., 2017; Kupfer et al., 2002), category cutoff points that determine who does and who does not receive treatment lack validity and thus may have a negative impact on the public health.

Many of the limitations of this rational approach to nosology are addressed by using empirical, quantitative methods to understand the dimensional structure of psychological dysfunction. Achenbach (1966) first extracted higher order "internalizing" and "externalizing" factors from indicators of mental disorder in adolescents. A central aspect of this work was the finding that there was substantial covariance among symptoms within what was labeled 
internalizing and within what was labeled externalizing. The internalizing dimension was primarily defined by anxiety and depression, affecting primarily the individual patient, and the externalizing dimension by aggressive and delinquent behavior, affecting other people in the patient's life. These higher-order factors of psychopathology were then examined across 10 mental disorders and adapted to fit their manifestation in adults, with internalizing largely similar and externalizing including antisocial behavior and substance use problems (Krueger, 1999). These studies suggested that co-occurring psychopathology may, in part, result from symptomatology common to both internalizing and externalizing processes.

Although the terms "internalizing" and "externalizing" may be read to imply separate, or even opposite, processes, empirical studies consistently demonstrate that internalizing and externalizing factors have been found to be highly correlated (Conway et al., 2019; du Pont et al., 2018). The two were correlated $r=.51$ in adults (Krueger 1999), $r=.72$ in adolescents (Cosgrove et al., 2011), and $r=.66$ in children (Lahey et al., 2004). Clearly, the two dimensions share a significant amount of variance. Individuals elevated on the internalizing dimension tend also to be elevated on the externalizing dimension, and vice versa. This empirical finding set the stage for the investigation of an even broader factor of psychopathology, now known as p.

\section{Structural and criterion validity of $\mathbf{p}$.}

Noting the shared variance between internalizing and externalizing factors, Lahey and colleagues (2012) tested the empirical viability of one general factor of psychopathology. They used a bifactor model to examine general and unique factors of psychopathology (Figure 1). All indicators of psychopathology loaded on the general bifactor, and the general bifactor model fit the data somewhat better than a correlated-factors model, i.e., a model specifying internalizing 
and externalizing dimensions that are correlated with each other. Crucially, the general bifactor predicted external criteria. The bifactor model also allowed for specific internalizing and externalizing factors, independent of the general factor: both of those factors also displayed unique criterion-related validity associations. This study provided initial support for a general psychopathology factor, while also indicating the additional value of looking at specific dimensions.

Caspi and colleagues (2014) examined the higher-order factor structure of psychopathology using data collected across 20 years spanning adolescence to middle-age. Indicators of substance use and conduct disorder/antisocial behavior defined an externalizing factor; indicators of depression, anxiety, and fear defined an internalizing factor; and indicators of obsessive-compulsive disorder (OCD), mania, and schizophrenia defined a "thought disorder" factor. The bifactor model displayed better fit to the data than one-factor or correlated threefactors models. Thought disorder variables in the bifactor model loaded strongly onto $\mathrm{p}$, despite also having their own specific factor. Additional analyses revealed that model fit was best when the specific thought disorder factor was removed and individual thought disorder symptoms were allowed to load directly onto the $\mathrm{p}$ factor. This was interpreted as an indication that thought disorder symptoms are a primary indicator of $\mathrm{p}$. In criterion-related validity analyses, the $\mathrm{p}$ factor predicted over 20 self-report, behavioral, and brain measures of life impairment over and above the internalizing and externalizing factors. The final revised model has served as the basis for many subsequent investigations of the $\mathrm{p}$ factor.

Several studies have replicated the finding that a bifactor model specifying a general factor, along with specific internalizing and externalizing factors, performs best in studies of children (Sallis et al., in press; Waldman et al., 2016), adolescents (Castellanos-Ryan et al., 
2016; Laceulle et al., 2015), and adults (Caspi et al., 2014; Lahey et al., 2012). However, support has also been found for variants of this model. For example, Stochl and colleagues (2015) found support for a bifactor model with a general factor, a psychotic experiences specific factor, and a composite depression/anxiety specific factor. Internalizing is sometimes split into separate fear and distress factors (Greene \& Eaton 2017; Lahey et al., 2012; Martel et al., 2017). Other firstorder factors have also been extracted with good fit such as eating pathology, somatization, and attention-deficit hyperactivity disorder. Many $\mathrm{p}$ factor studies do not include indicators of thought disorder, or psychotic/obsessive-compulsive symptoms (Caspi et al., 2014), instead focusing on modeling internalizing (e.g., depression and anxiety) and externalizing (e.g., substance abuse and antisocial behavior). However, when measures of thought disorder are included in the statistical modeling of $\mathrm{p}$, they tend to display the largest loadings on $\mathrm{p}$ (Caspi et al., 2014; Oltmanns et al., 2018).

The majority of studies investigating the structure of psychopathology in adults use categorical diagnoses, which have important limitations, as discussed previously (Kotov et al., 2017). In light of this, Lahey and colleagues (2017) constructed models based on dimensions of psychopathology — rather than discrete disorders — and tested the boundaries of the p-factor through a series of factor analyses. They used self-reported symptom counts for 14 dimensions of psychopathology in their model, given that symptoms of psychopathology are related to distress and impairment regardless of whether or not a diagnostic threshold is met (Copeland et al., 2015; Fergusson et al., 2005; Roberts et al., 2015). Confirmatory factor analyses found that a bifactor model fit the data well. Model tests with and without symptoms common to multiple psychiatric disorders yielded essentially identical results, suggesting that $\mathrm{p}$ is not an artifact caused by symptoms which are common to multiple disorders (Lahey et al., 2017). Further, 
Lahey and colleagues (2017) conducted a series of analyses in which each first-order dimension of psychopathology was removed from the best fitting model. Each of the 14 tested models fit the data well, suggesting that no first-order dimension was critical to the identification of $\mathrm{p}$. These results provide evidence for the robustness of $\mathrm{p}$ as well as support the use of dimensions of psychopathology over categorical diagnoses.

Many other studies support the criterion validity of $\mathrm{p}$. Longitudinally, a general factor of psychopathology (assessed in children, whether via parent-report or using multiple informants) predicted adverse mental health outcomes later in adolescence above other latent factors included in the model (Pettersson et al., 2018; Sallis et al., 2019). Negative outcomes predicted include psychiatric diagnoses, court convictions, poor academic performance, criminal behavior, and affective symptoms later in life above and beyond specific internalizing and externalizing factors. $\mathrm{p}$ has also been associated with suicide attempts, non-suicidal self-injury, and drinking (Conway et al., 2019; Riley et al., 2019), impulsivity and hopelessness (Castellanos-Ryan et al., 2016), lower executive functioning (Martel et al., 2017), and reduced fetal growth (Pettersson et al., 2019). These results, together with other results outlined above (e.g., Caspi et al., 2014; Lahey et al., 2012), provide compelling evidence for the criterion validity of $\mathrm{p}$ and suggest that the general factor of psychopathology may have a significant impact on life outcomes.

\section{Genetic basis of $\mathbf{p}$}

Studies increasingly suggest p has, in part, a genetic basis (Lahey et al., 2017; Neumann et al., 2016). Lahey and colleagues (2017) summarized several genetic studies on the p factor using both independent and common pathways modeling. Independent pathways studies examine genetic influences on specific forms of psychopathology and have demonstrated that "genetic 
influences tend to be robustly shared across multiple dimensions of psychopathology" (Lahey et al., 2017, p. 156). Indeed, a general genetic factor influencing all dimensions of psychopathology was identified in four of these studies (Lahey et al., 2011; Pettersson et al., 2013; Pettersson et al., 2016; Spatola et al., 2007). Not surprisingly, variations in symptom profiles were also a function of environmental contributors (Lahey et al., 2011). Common pathways studies, which assume that genetic influences on specific psychopathology operate through meaningful higherorder factors, have found that much of the overlap between internalizing and externalizing factors is due to common genetic influences (Cosgrove et al., 2011; Lahey et al., 2017; Wolf et al., 2010). Lahey et al. (2017) found the estimated heritability of the $\mathrm{p}$ factor to $b e \mathrm{~h}^{2}=.43$ in a large sample of adolescents. There is strong evidence tying genetic influences to variability in overall psychopathology.

\section{Stability of p over time}

$\mathrm{p}$ factor scores are strikingly stable over time in childhood, adolescence, and adults. Over eight intervals from age 2 to 14 , stability coefficients ranged from .52 to .76 (McElroy et al., 2018). In another study also over eight intervals, in this case from age 10 to age 16, coefficients ranged from .65 to .76 (Riley et al., 2019). Stability in adolescents over 18 months to two years ranged from .73 to .86 (Castellanos-Ryan et al., 2016; Snyder et al., 2017); among adults across a three to four year interval, a stability coefficient of .65 has been reported (Greene \& Eaton 2017). Thus, in aggregate, individual differences in $p$ appear to be stable over time. The consistency of the stability estimates across studies is particularly noteworthy, given that $\mathrm{p}$ values are estimated based on different measures of specific psychopathology in each study. 
It should be noted that Murray et al. (2016) found much lower stability estimates across eight waves from childhood to adolescence (values range from .10 to .33). There are important differences between the approach taken by Murray and colleagues and that taken in the other studies. They did not calculate p using a confirmatory bifactor model; rather, they used an exploratory approach that did not constrain cross-loadings to zero and required symptom loadings on $\mathrm{p}$ to be the same across time. Complicating interpretation of these findings, Murray and colleagues used a single, 39-item measure to reflect $\mathrm{p}$.

It seems quite possible that $\mathrm{p}$ is generally stable over time, but specific symptom expressions of impairment vary across assessment occasions. It is well documented that individuals vary in their experiences of distress over time: depression and anxiety symptoms increase and decrease, as do rates of substance use, delinquent behavior, and most disorders (Brook et al., 2013; Evans et al., 2016; Flory et al., 2004; Keel et al., 2007; Xiang \& Cheng in press). Indeed, one of the things that is noteworthy about the finding of stable $\mathrm{p}$ is that it appears to be the case that, despite variations in individual symptom expression over time, individuals have relatively stable levels of overall psychopathology. Recognizing this reality is important both theoretically, as one considers underlying causes of psychopathology (Lahey et al., 2011), and clinically. As we discuss below, treatment of a specific symptom or disorder is likely to vary markedly if the client is low or high in $\mathrm{p}$.

It is also important to recognize that, despite high stability coefficients, $\mathrm{p}$ is far from perfectly stable over time. We presume that there are three broad sources of whatever instability is present. The first is measurement: stable p estimates depend on the reliability, validity, and stability of the symptom measures that are expressions of p. Given the inevitability of imperfect 
measurement across multiple measures in each p study, one could not reasonably expect stability estimates near unity even if $\mathrm{p}$ was perfectly stable.

The second source of instability is substantive. Perhaps as a function of variations in life stress that join with a given person's diathesis, individuals vary in the degree to which they experience impairing symptoms. For example, when someone whose main form of pathology is an eating disorder has a significant negative life experience, resulting in a symptom spike, that person may be more likely to have elevated anxiety, panic, depression, and/or interpersonal problems as well. If so, a symptom spike in one area could lead to a higher estimate of $\mathrm{p}$ for that person than would be the case when the person is experiencing lower levels of stress, and hence fewer symptoms.

We suggest the third source of instability involves variation in access to, and nature of, treatment. We know there is significant variability in the quality of mental services available for many reasons, including as a function of the race of the prospective client (Health and Human Services 2001). As one specific example, clinicians tend to be unaware of, or insensitive to, cultural differences in behaviors that may or may not be symptoms of dysfunction (Lopez \& Guarnaccia 2005; Moleiro 2018; Whaley 1997). As a result of these and other processes, it is likely that, both between people and within a person over time, there is variation in access to, and the quality of, treatment. This variation may be another reason why people's symptom levels, and hence $\mathrm{p}$ estimates, differ at different times.

One possible theoretical frame for understanding the stability of $\mathrm{p}$ is that each person has a core level of $\mathrm{p}$. As a function of variations in life circumstances, stressors, and treatment resources available, at any one time a person's level of $\mathrm{p}$ will fall somewhere in a bandwidth 
around the person's core level of $\mathrm{p}$. Those who experience greater fluctuations in life stress, and those who experience greater variation in access to quality mental health treatment provision, may experience greater fluctuations in momentary p: the bandwidth around their core $\mathrm{p}$ will be greater. Those with consistent access to quality mental health care and who experience less fluctuation in life stress, may have less variability in momentary $p$ : their $\mathrm{p}$ bandwidth will be smaller. The value of such a theoretical frame has yet to be determined.

\section{Statistical modeling of p: Implications.}

Researchers have used different statistical approaches to modeling $\mathrm{p}$, including bifactor models (Figure 1), single-factor (unidimensional) models (Figure 2), and to a lesser extent higher-order factor models (Figure 3: Castellanos-Ryan et al., 2016; Conway et al., 2019; Martel et al., 2017; Waldman et al., 2016). An important question is whether the substantive meaning of $\mathrm{p}$, as well as the substantive meaning of lower level factors, such as internalizing and externalizing, differ as a function of how those factors are defined. In bifactor models, $\mathrm{p}$ is extracted from all indicators (i.e., variables) in the model, and typically, orthogonal internalizing and externalizing factors are also extracted. In single-factor models, one factor explains the shared variance among all the indicators of psychopathology—it is the only factor extracted, and it is conceptualized as $\mathrm{p}$. In the higher-order factor model, $\mathrm{p}$ is extracted above first-order factors such as internalizing and externalizing. This means that the variance in p comes from the overlap between internalizing and externalizing: $\mathrm{p}$ reflects the variance the two factors share. Conway et al., (2019) provided enlightening information about the differences between higher-order and bifactor models of $\mathrm{p}$ in a large dataset of students who had sought treatment for mental health (N $=25,002)$. Two versions of the $\mathrm{p}$ factor - one derived by bifactor and one by higher-order modeling - correlated $r=.97$, indicating that the $\mathrm{p}$ factor is the same when using higher-order or 
bifactor methods to extract it. Not surprisingly, the two versions of $\mathrm{p}$ demonstrated very similar levels of criterion validity coefficients with suicide attempts, non-suicidal self-injury, and alcohol use (Conway et al., 2019).

In contrast, the meaning of internalizing and externalizing factors appears to differ substantially as a function of method of factor extraction. It is important to appreciate that in bifactor models, the internalizing and externalizing factors include none of the variance that is shared across all disorders; the two factors are independent of $\mathrm{p}$. When so modeled, they are often negatively correlated (Caspi et al., 2014; Laceulle et al., 2016; Neumann et al., 2016; Tackett et al., 2013). In all likelihood, the high positive correlations between internalizing and externalizing factors found when $\mathrm{p}$ is not extracted reflects the reality that both factors include variance shared across all disorders. When such variance is removed, what is left to be modeled as internalizing and externalizing is necessarily substantively different.

Researchers are just beginning to investigate the substantive meaning of internalizing and externalizing with $\mathrm{p}$ removed. It may essentially reflect different forms of expression of distress (inward or outward), independent of overall distress level, but that is just one possibility to be investigated through construct validity studies. Conway and colleagues (2019) found the specific internalizing and externalizing factors difficult to model and could draw no confident conclusions about them.

\section{p COMPARED WITH GENERAL FACTORS OF PERSONALITY (GFP) AND PERSONALITY DISORDER (g-PD)}

In addition to the $\mathrm{p}$ factor, general factors of personality and personality disorder have also been identified. However, these literatures have been largely separate from one another, and 
the relations between general factors across these domains have been unclear. Digman (1997) extracted higher-order factors from the five-factor model (FFM) of personality, which he named alpha and beta (later called stability and plasticity; DeYoung et al., 2002). The higher order alpha/stability factor captures variance shared among agreeableness, conscientiousness, and neuroticism (the last with a negative loading), while the higher order beta/plasticity factor captures variance shared among extraversion and openness. Musek (2007) noted consistent correlations between the domains of the five-factor model, as well as between alpha and beta, and extracted a general factor of personality over and above alpha and beta across three independent samples. Models including a GFP displayed satisfactory confirmatory fit indices and exploratory factor structure across the samples and across most popular measures and models of personality (Rushton \& Irwing 2011).

There is significant debate within the personality literature about whether the GFP is composed of variance that is substantive or non-substantive (Irwing 2013; Revelle \& Wilt 2013). This makes sense, especially given the difficulty of conceptualizing all five factors of personality as one - that is, what could be the meaning of one factor of personality that combines all five factors? However, some authors do offer substantive conceptualizations of GFP. For example, Musek interpreted the GFP as "positive versus negative aspects of personality" (p. 1228). One of the most prominent substantive interpretations of the GFP is as an individual differences continuum of social effectiveness (van der Linden et al., 2016).

Within the literature on the GFP, there are several areas of investigation suggesting that the GFP is not meaningful: It has been found that the saturation of the general factor is significantly reduced when it is modeled with multi-method assessments (Davies et al., 2015), the GFP correlates $r=.86$ with a factor of items reflecting evaluation (positive loadings on 
happy, cooperative, and rational; negative loadings on sluggish, manic, and grim; Pettersson et al., 2012), the GFP is reduced when evaluative content is removed from the items assessing it (Bäckström et al., 2009), and items with opposite meanings appear to load in the same direction on the general factor (Pettersson et al., 2012).

However, there are reasons why the above findings may not speak to the meaningfulness of GFP. First, it would make sense that the variance in the GFP would be reduced with multimethod assessments, as self-other agreement on personality is typically moderate (Connelly \& Ones 2010), and indeed most of the variance in same-method assessments of personality is unique. Second, the Pettersson et al. (2012) measure of evaluation does appear to reflect traits associated with a dimension of successful versus unsuccessful functioning. It thus may have meaning with respect to broad adjustment/impairment. This possibility is developed further below. Indeed, it has been demonstrated that measures of social desirability typically contain more substantive personality traits than evaluation bias (McCrae \& Costa 1983; Kurtz et al., 2008). Third, there is an alternative explanation for why items with opposite meanings would load in the same direction. We present that explanation below.

More fundamentally, there is an enormous body of evidence documenting the concurrent and predictive validity of personality traits in numerous domains of functioning, including physical health, psychological health, mortality, marital outcomes, interpersonal functioning, educational and occupational attainment, life happiness, engagement in substance abuse, and psychopathology (Costa \& McCrae 1996; Ozer \& Martinez 2006; Roberts et al., 2007). It thus seems implausible that the core variation reflected by such measures is simply socially desirable reporting. In short, GFP reflects shared variance among many traits, each of which has been 
shown to have substantive meaning. The meaning of GFP itself is not yet clear but may involve a general dimension of successful versus unsuccessful functioning.

A general factor of personality disorder (g-PD) has also been extracted from measures of DSM-IV personality disorder and DSM-5 Alternative Model of Personality Disorder maladaptive personality traits (Jahng et al., 2011; Oltmanns et al., 2018; Sharp et al., 2015; Williams et al., 2018; Wright et al., 2016). Loadings on the g-PD are often composed of borderline, avoidant, and dependent personality disorder traits, but have varied from study to study. Interpretations of the g-PD have been substantive: It has been interpreted as interpersonal dysfunction (Jahng et al., 2011), borderline personality disorder, and self-other deficits typical of Criterion A of the Alternative Model of Personality Disorder (Sharp et al., 2015; Wright et al., 2016). For example, one study at the symptom level found that borderline personality disorder defined the g-PD and there were no specific factors, leading to the potential conclusion that the g-PD might be defined by borderline personality disorder (Sharp et al., 2015). There have been no studies of the g-PD that put forward non-substantive interpretations (i.e., that the variance in the $\mathrm{g}-\mathrm{PD}$ is artifactual).

Oltmanns et al. (2018) noted that the literatures on general factors of psychopathology, personality, and personality disorder, respectively, were largely separate from one another. They measured all three general factors together in one self-report dataset and found high correlations amongst them (the $\mathrm{p}$ factor correlated $r=.92$ with the g-PD and $r=-.70$ with the GFP and the gPD and GFP correlated $r=-.90)$. In a second dataset containing multi-method assessment of personality and personality disorder, the GFP and g-PD were correlated $r=-.82$. The correlations of the $\mathrm{p}$ factor and g-PD with the GFP were negative, because more positive (or desirable) traits loaded positively and more negative (or undesirable) traits load negatively on the GFP, whereas 
positive loadings on $\mathrm{p}$ and g-PD reflect higher levels of dysfunction. The correlations among the three general factors were quite high, providing evidence that whatever explains the GFP and gPD may be the same as what explains the $\mathrm{p}$ factor. It certainly argues against the likelihood that explanations for $\mathrm{p}$, GFP, and g-PD are markedly different.

\section{CAUSAL INFLUENCES FOR PSYCHOPATHOLOGY}

Certainly the recognition of a general factor for psychopathology, as well as for personality and personality disorder, suggests the possibility of a common cause or causes that contribute to multiple forms of dysfunction. The finding of heritability for $\mathrm{p}$ supports this inference strongly. Lahey and colleagues (2017) argue that global risks for general dysfunction combine with more specific, disorder-specific risks to account for the emergence of psychopathology.

\section{SUBSTANTIVE INTERPRETATIONS OF THE p FACTOR}

We outline here four different substantive interpretations of the p-factor from the literature. In the following section, we provide a critical evaluation of each.

\section{Dispositional negative emotionality.}

One proposed hypothesis is that $\mathrm{p}$ reflects dispositional negative emotionality (Lahey et al., 2017; Tackett et al., 2013). Tackett, Lahey, and colleagues (2013), in a large cross-sectional study of adolescent twins, found support for a bifactor model with a general bifactor (p) and internalizing and externalizing specific factors. Analyses showed that dispositional negative emotionality correlated more strongly with the $\mathrm{p}$ factor than with specific internalizing or externalizing factors. 
The negative emotionality hypothesis is based on the spectrum model of the relationship between personality and psychopathology, which suggests a shared etiology between personality and psychopathology (Widiger \& Smith 2008). The tendency to experience negative affect and distress is a stable and robust personality disposition (Watson \& Clarke 1984), and dispositional negative emotionality is implicated in a large portion of psychiatric disorders (Lahey 2009; Meijer et al., 2011). Research has also shown that, across samples and cultures, negative emotionality is one of the primary factors extracted from individual difference measures of personality (John et al., 2008; Lahey 2009; Markon et al., 2005). Further, studies suggest that negative emotionality shares a significant amount of genetic influence with other forms of psychopathology (Mikolajewski et al., 2013; Olrmel et al., 2005). Taken together, this body of research suggests the possibility that severity of psychopathology may reflect an individual's tendency toward dispositional negative emotionality, regardless of diagnosis.

\section{Impulsive responsivity to emotion.}

Another proposed hypothesis posits that $\mathrm{p}$ reflects impulsive responsivity to emotion (Carver et al., 2017). Research suggests that deficits on behavioral measures of response inhibition are related to both internalizing and externalizing disorders (Smith et al., 2013; Wright et al., 2014). Deficits in response inhibition have also been observed in thought disorders such as obsessive-compulsive disorder, bipolar disorder, and schizophrenia (Abramovitch et al., 2013; Bora et al., 2009; Mesholam et al., 2009). One meta-analysis revealed that deficits in response inhibition observed in individuals with thought disorders were as large or larger than deficits associated with internalizing or externalizing psychopathology (Wright et al., 2014). This is particularly notable given that thought disorders tend to load highest on p (Caspi et al., 2014; Oltmanns et al., 2018). 
Beyond broad behavioral disinhibition, there is a substantial body of evidence which suggests that emotion-based impulsive action is related to various forms of psychopathology (Carver et al., 2008; Cyders \& Smith 2008a; Smith \& Cyders 2016). Several studies support a strong positive association between self-report measures of emotion-based impulsive actions and both internalizing and externalizing psychopathology (Berg et al., 2015; Carver et al., 2013; Cyders \& Smith 2008b; Cyders et al., 2009; Fischer et al., 2008; Johnson et al., 2013; Pearson \& Smith 2015; Peterson et al., 2018; Riley et al., 2015; Settles et al., 2010; Smith et al., 2013; Zapolski et al., 2009). Research also indicates preliminary support for associations between emotion-based impulsive actions and bipolar disorder (Muhtadie et al., 2014), schizophrenia (Hoptman et al., 2014), and obsessive-compulsive disorder (Cougle et al., 2012). Tendencies toward impulsive action are included in criteria for multiple DSM disorders. While $\mathrm{p}$ has been linked to negative emotionality and deficits in response inhibition separately, the hypothesis that p reflects emotion-based impulsivity has not been tested empirically.

\section{Low cognitive functioning.}

A third substantive interpretation is that high levels of $\mathrm{p}$ reflect low cognitive or intellectual functioning. Studies have shown that higher levels of $\mathrm{p}$ are associated with worse performance on tests of executive functioning. Specifically, individuals with higher levels of $\mathrm{p}$ perform worse on tests of attention, concentration, processing speed, and visual-motor coordination compared to those with lower levels of p (Martel et al., 2017). Additionally, studies that found a relationship between cognitive functioning and $\mathrm{p}$ showed that the deficits in cognitive functioning observed in individuals with high levels of $\mathrm{p}$ were present before the onset of most psychiatric disorders (Caspi \& Moffit 2018). This suggests the possibility of a causal pathway from cognitive functioning deficits to development of psychiatric disorders. Caspi and 
Moffit (2018) also note the possibility that deficits in cognitive functioning may underlie p given that low cognitive ability has been shown as a marker for neuroanatomical abnormalities.

Neuroanatomical abnormalities, in turn, have been shown to increase vulnerability to psychiatric disorders. Further, low cognitive ability reduces mental health literacy and is related to increased exposure and vulnerability to life stressors (Alnaes et al., 2018; Koenen et al., 2009). This suggests that individuals with low cognitive functioning are more likely to experience significant distress over their lifetime but may be less likely, on average, to seek professional help when needed.

\section{Thought dysfunction.}

Lastly, Caspi and Moffit (2018) suggest the possibility that p reflects disordered thought processes common to almost all psychiatric disorders. They suggest that individuals with high levels of p may experience psychotic thought processes regardless of their diagnosis. Psychotic thought processes, in this context, are not limited to delusions and hallucinations. Rather, they may entail problems such as irrational fears, intrusive thoughts, and re-experiencing trauma. This hypothesis suggests that psychotic disorders reflect the highest levels of $\mathrm{p}$, which is consistent with prior evidence suggesting that thought disorder symptoms load most highly on p compared to internalizing or externalizing symptoms.

\section{LIMITATIONS OF SUBSTANTIVE INTERPRETATIONS OF THE p FACTOR}

The $\mathrm{p}$ factor has been shown consistently to emerge from data measuring broad arrays of psychopathology. Several hypotheses have been put forward to ascribe substantive meaning to the shared variance across forms of psychopathology. What is it that different symptoms of 
psychopathology, for example substance abuse, OCD, depression, hallucinations and delusions, and personality disorder have in common?

Each of the four main substantive hypotheses outlined in the prior section focus on specific components of maladaptive functioning: Negative affectivity, impulsive reactivity to emotion, low cognitive functioning, and thought dysfunction. There have been convincing studies that indicate the $\mathrm{p}$ factor overlaps with these dispositions and impairments (Caspi \& Moffitt 2018; Lahey et al., 2017; Smith \& Cyders 2016; Tackett et al., 2013).

A potential problem with these interpretations arises, though, when thinking more specifically about the variables that load together on p. It is unclear how these four substantive interpretations of $\mathrm{p}$ explain the variance for all of the variables loading on $\mathrm{p}$. Consider these examples: If negative affectivity cannot explain a hallucination item that loads on $\mathrm{p}$, such as "I

see things that other people do not see," it is not clear how it could be the core of $p$. If impulsive responsivity to emotion cannot explain an anhedonia item such as "I do not feel pleasure," which loads on the $\mathrm{p}$ factor, it may not be the core of $\mathrm{p}$. If low cognition or thought dysfunction cannot explain an ADHD hyperactivity item that loads on the p factor, such as "I talk excessively," neither may be the core of $\mathrm{p}$.

\section{Impairment}

An alternative to specific, substantive interpretations of $\mathrm{p}$ is that $\mathrm{p}$ is simply an index of overall impairment that is nonspecific and secondary to the variables that load on the $\mathrm{p}$ factor (Oltmanns et al., 2018; Widiger \& Oltmanns 2017). Unlike current substantive interpretations of $\mathrm{p}$, the impairment interpretation is fully consistent with the existing literature on p. First, it is consistent with the typical order of variable loadings on the p factor: Indicators of psychosis and 
mania_-which cause the most impairment in a person's life — typically load highest, followed by more common internalizing and externalizing mental disorder symptoms, which cause relatively less impairment (Lahey et al., 2017). Variables with less associated life impairment have lower loadings on the $\mathrm{p}$ factor, and indeed, the $\mathrm{p}$ factor negatively predicts desirable outcomes (Caspi et al., 2014). Second, it is consistent with the wide range of outcomes that have been correlated with the $\mathrm{p}$ factor. The $\mathrm{p}$ factor has been associated with almost every undesirable outcome studied to date: Cognitive deficits, childhood abuse, court convictions, academic achievement, antisocial behaviors, and so on (Caspi et al., 2014; Martel et al., 2017; Pettersson et al., 2013; Sallis et al., 2019).

Third, the impairment interpretation explains the higher-order factors as well as symptoms and traits at the item-level. It is clearer how an interpretation of impairment would explain each of the examples from above: "I do not feel pleasure," "I see things that other people do not see," and "I talk excessively," as well as classic impulsive responsivity to emotion, negative affectivity, and thought dysfunction items (e.g., "I am quick to respond with anger," "I often feel depressed," and "My thoughts are alien to me," respectively). All of them share that they would cause impairment in a person's life. Conceptualizing the $\mathrm{p}$ factor as impairment also accounts for why items loading positively on p may have different and at times opposite meanings (e.g., sluggish and manic). That is, being sluggish or manic can both result in the failure to complete tasks effectively, yet for opposite reasons. The impairment hypothesis is, further, common to all three domains (the p factor, GFP, and g-PD) and can be used to interpret the GFP and the g-PD. High scores on p associate strongly with high scores on overall personality dysfunction. High scores on p also associate strongly with low scores on a factor reflecting the evaluative content in personality measures. Concerning the latter, traits associated 
with health will be evaluated more positively, and traits that cause impairment will be evaluated more negatively. The positive-versus-negative aspects of personality interpretation of the GFP is similar to the evaluative hypothesis (Musek 2007). It is not completely a substantive interpretation and it aligns well with the impairment hypothesis. Traits that cause more impairment will be more negative aspects and traits that cause less impairment or promote health will be more positive aspects. In sum, the interpretation of the $\mathrm{p}$ factor as a continuum from low impairment to high impairment appears to account for loadings on the p factor, as well as p's association with GFP and g-PD.

The substantive interpretations of the GFP and the g-PD have similar limitations as substantive interpretations of $\mathrm{p}$, in that they do not appear able to explain loadings at the item level. For example, if social effectiveness explained the GFP, it is unclear how it would explain the impulsiveness item "I have trouble controlling my food cravings." If borderline personality disorder explained the g-PD, it is unclear how it would explain the schizoid item, "I am not interested in sex." If interpersonal dysfunction explained the g-PD, it is unclear how it would explain the schizotypal personality disorder item, "I am a very superstitious person." In contrast, the impairment interpretation again explains what all of these items may share - they all would be associated with impairment in a person's life. Just as is true with p, the impairment interpretation does not have the shortcomings experienced by substantive interpretations of GFP and g-PD.

It is perhaps also noteworthy that $\mathrm{p}$ as impairment is parallel to interpretations of $g$, the general factor of intelligence. If one considers the classic Wechsler model of intellectual functioning, there is substantive meaning to lower level scores, such as on a measure of vocabulary, and substantive meaning to clusters of such scores, such as verbal functioning. $g$ 
reflects the variance shared across several substantive domains: verbal, spatial, working memory, processing speed, fluid reasoning. Its classic interpretation by Wechsler was "the aggregate or global capacity of the individual to act purposefully, to think rationally and to deal effectively with his environment (Wechsler 1944, p. 3)." Such a definition is abstract and does not connote a specific, substantive cognitive process. In the same way, $\mathrm{p}$ as impairment is abstract and does not connote a specific, substantive psychological process.

Given the consistently replicated finding that $\mathrm{p}$ accounts for substantial variance in psychopathology, an important question is whether consideration of $\mathrm{p}$ has clinical utility. We next turn to this question.

\section{THE CLINICAL UTILITY OF p}

If $\mathrm{p}$ were best understood as reflecting a specific substantive domain of functioning, such as negative emotionality, impulsive responses to emotion, or disordered thought, $\mathrm{p}$ is likely to have very direct, clear clinical utility. Interventions designed to address the substantive domain would be expected to influence overall dysfunction and thus should be a focus of clinical science. Indeed, because of a recent focus on transdiagnostic interventions, such efforts are well underway. For example, focus on treating elevations in Neuroticism may reduce multiple specific expressions of subjective distress (Sauer-Zavala et al., 2017). Similarly, efforts to treat the personality trait of urgency (the disposition to act rashly when emotional: Cyders \& Smith 2008a), thought to underlie impulsive responding to emotion, are in development (Weiss et al., 2015). Transdiagnostic interventions like these are likely to be very useful, even though, as described above, they may not be applicable to all of psychopathology. 
An important question is whether $\mathrm{p}$ has clinical utility if it is not understood to have substantive meaning. We argue that $\mathrm{p}$, understood as an index of overall impairment, is likely to have a great deal of clinical utility. We next present the rationale for this claim.

To understand the clinical utility of $\mathrm{p}$ as an index of overall impairment, we argue that the presence of $\mathrm{p}$ must be understood along with other findings pointing to the value of focusing on lower level, homogeneous constructs (McGrath 2005; Smith et al., 2003; Smith \& McCarthy 1995; Strauss \& Smith 2008). Consider two facets of Neuroticism as measured by the NEO PI-R. Angry hostility and self-consciousness, both facets of Neuroticism, share just $14 \%$ of their variance. One person could be high in angry hostility and low in self-consciousness, and another could be low in angry hostility and high in self-consciousness. Those two individuals could have exactly the same score on Neuroticism as measured by the NEO PI-R, even though they relate to the world in very different ways. Indeed, the two lower-level traits have importantly different correlates. For example, the consensus view of psychopathy, based on both expert ratings and measurement, involves being unusually high in angry hostility and unusually low in selfconsciousness (Lynam \& Widiger 2007). From this perspective, it makes sense to develop theories relating angry hostility to other constructs, or self-consciousness to other constructs, and tests of such theories would be coherent. However, a theory relating overall Neuroticism to other constructs must be imprecise and unclear because of the substantial unrelated variance of the lower level variables. For example, if Neuroticism correlates with another measure, one does not know which of the two traits account for the covariation, or even whether the same traits account for the covariation for each member of the sample.

Extending this logic further, the use of a p score, obtained as a summation of scores on several, separable traits, has both value and limitations. On one hand, it can provide an index of 
someone's overall level of impairment, which we now know to be a relatively stable part of that person's experience. On the other hand, it cannot provide a precise description of the nature and form of the person's impairment. Because $\mathrm{p}$ accounts for substantial variance in impairment, clinical scientists should want to know a client's level of $\mathrm{p}$. At the same time, because the specific variance for lower level constructs can also be substantial, clinical scientists should want to understand a person's levels of specific forms of impairment as well.

There are times when appreciating differences in specific clinical constructs is crucial. Within affective disorders, anhedonia can be treated using behavioral interventions that are exposure-based (Chambless \& Ollendick 2001; Dimidjian et al., 2006). High levels of negative affect often benefit from interventions focusing on changes in cognition, typical of cognitive behavioral therapy (Chambless \& Ollendick 2001). Because both anhedonia and elevated negative affect can characterize depression, recognition that clients can have different levels of the two constructs results in different treatment approaches even within a single disorder. Recognition of the presence of $\mathrm{p}$ does not diminish the value of focusing on lower-level, specific forms of dysfunction.

\section{$P$ assessment for treatment planning and establishing treatment goals. If $\mathrm{p}$ is}

understood to be an index of overall impairment, knowing a client's level of $\mathrm{p}$ is crucial for developing effective treatment plans, determining treatment goals, funding the necessary duration of treatment, and relieving distress secondary to one's impairment. A client presenting for treatment who has a high level of $\mathrm{p}$ can be expected to endorse distress across multiple symptoms associated with multiple disorders. This may manifest as psychiatric comorbidity from the DSM perspective, which is quite common (Ulfvebrand et al., 2015). In terms of outcomes, psychiatric comorbidity is thought to increase disorder severity, contribute to a chronic course of 
illness, and be associated with less successful treatment (Blinder et al., 2006; Milos et al., 2013). By contrast, a person presenting for treatment with a low level of $\mathrm{p}$ is likely to have fewer problems and thus a more positive prognosis, requiring treatment of shorter duration. We illustrate these considerations using two clinical case examples.

Patient A. Patient A is a 20-year-old cisgender female college student of normal weight presenting with symptoms of bulimia nervosa $(\mathrm{BN})$. She endorsed binge eating two to three times per week, and compensatory behaviors (self-induced vomiting and fasting for 8 hours or more) daily. She denied any current or past symptoms of depression, anxiety, or problem substance use. She denied ever being underweight and stated her eating disorder began about six months ago. Patient A admitted to having interpersonal issues related to her disordered eating including feeling afraid to eat out at restaurants with her friends for fear of consuming over her daily calorie limit. However, she reported no distress unrelated to her eating disorder and reported having excellent grades and a strong social support network. Given these reports, patient A's therapist recommended the first-line treatment for $\mathrm{BN}$ - Enhanced Cognitive Behavioral Therapy (CBT-E: Fairburn et al., 2009 ) - and petitioned for 20 outpatient treatment sessions from the patient's insurance company.

Patient B. Patient B is also a 20-year-old cisgender female college student of normal weight presenting with symptoms of bulimia nervosa (BN). She endorsed binge eating and compensatory behaviors at a similar frequency as Patient A, and also stated these behaviors began about six months ago. Patient B also endorsed fear of overconsumption and discomfort around eating with others. However, she reported a history of anorexia nervosa (AN) and had been fluctuating between average weight and underweight for the past five years. Unlike Patient A, Patient B also endorsed daily nonsuicidal self-harm behaviors, which sometimes required 
medical attention. She reported depression symptoms concurrent with her disordered eating. She reported frequent thoughts of suicide and had survived a suicide attempt 8 months ago. She reported often feeling numb, and sometimes engaged in self-harm behavior in response to that feeling. She recently was told she is not on track to finish the prerequisites for her nursing major on time, and is on the cusp of losing her college scholarship due to a drop in her grades and GPA over the past year. She reported a spike in her suicidal thoughts in response to the news that she may lose her scholarship. Given Patient B's mental health history, variety of current symptoms reported, and her multifaceted distress, her initial assessment therapist recommended she begin an intensive outpatient program with a treatment team of multidisciplinary providers.

Patients A and B both presented to treatment with eating concerns. When asked only about their disordered eating symptoms, they appeared quite similar. However, upon further questioning, their clinician discovered that their mental health histories and current distress differentiated their presentations. In our view, Patient A is an example of an individual with a low level of p. Her pathology is specific and somewhat isolated. Her eating disorder is uncomplicated by the presence of multiple symptoms of other disorders and a long history of psychological difficulty. Her distress is impairing and stems predominantly from her eating disorder (i.e. eating out with friends, feeling restricted in the foods she is comfortable eating, etc.), but she is still able to succeed in school and maintain her relationships. Given this straightforward presentation and the effectiveness of CBT-E, her prognosis is good.

Patient B is an example of an individual with a high level of p. Her history demonstrates she has struggled with her mental health for many years. Her eating disorder is more complex given her history of being underweight and meeting criteria for $\mathrm{AN}$ - which has the highest mortality rate of any mental illness (Arcelus et al., 2011). Her distress extends beyond her eating 
disorder and affects multiple other aspects of her functioning - academic, relational, financial, and physical. Given these symptoms and her associated distress, it is unlikely that one treatment approach, or treatment from a single health care discipline, could adequately address her needs. Patient B's intensive outpatient treatment plan will likely include treatments provided by several different providers (i.e., psychologist, dietitian, psychiatrist), extend beyond treatment for BN, and involve a longer course of treatment than that recommended for Patient A.

The above example illustrates that individuals with different levels of $\mathrm{p}$ are likely to need different treatment plans. It is also possible, even likely, that the idea of successful treatment would look different for individuals with different levels of $\mathrm{p}$. For example, it may be that by the end of the 20-session CBT-E treatment course, Patient A would no longer be experiencing any significant symptoms of BN, she would have the skills to identify and cope with relapses in bulimic behaviors, and she may never need to come back to treatment. This form of treatment success seems reasonable and attainable.

In contrast, complete symptom reduction across all forms of distress may not be a realistic treatment goal for a client with high levels of $\mathrm{p}$, such as Patient B. Instead, it may be helpful to conceptualize "treatment success" differently from full symptom reduction. Perhaps measured improvements in quality of life might be more realistic (Engel et al., 2009). Suppose Patient B experiences improved ability to (a) monitor her symptoms over time, (b) utilize and engage a system of supportive resources, and (c) utilize a wide variety of skills, perhaps including skills to manage negative affect and/or disrupt impulsive responses to emotion. Should those improvements occur, she is likely to experience a notable increase in her quality of life, even absent successful treatment of all her symptoms. Variation in levels of $\mathrm{p}$ can help define treatment success in realistic ways that make success attainable. 
A valid assessment of $\mathrm{p}$ provides necessary and compelling information to those who fund mental health treatment, whether insurance providers, the person suffering from impairment, the family of the sufferer, or mental health agencies that set session limits for treatment. Although Patients A and B presented with the same disorder, also reporting patients' levels of $\mathrm{p}$ indicates that Patient A can reasonably be expected to receive effective treatment within 20 sessions, but Patient B is likely to need ongoing intervention from multiple providers to produce necessary benefits. Those who fund treatment could thus have realistic, reasonable expectations for treatment duration and plan accordingly.

Conducting a valid assessment of $\mathrm{p}$ and sharing the results of that assessment in a therapeutic way with clients may help alleviate distress secondary to the disorder, or distress about the distress. Clients with high levels of $\mathrm{p}$ are likely to have experienced multiple forms of distress over a lengthy period, and may well have found prior treatment to be difficult or unsuccessful. They may be self-critical and pessimistic about treatment. To hear that they have a high propensity for impairment, due to genetic and environmental influences outside of their control, can provide them a frame for understanding their daily experience. Just as learning one has diabetes makes it possible for the person to collaborate with the goal of symptom management, so learning one is high in p may make it easier for a client to collaborate in treatment goals designed to improve quality of life. If both the therapist and the client understand that the goal of treatment is not complete alleviation of all symptoms--but rather to develop a set of skills to manage dysfunctional propensities--they are more likely to collaborate on the pursuit of realistic treatment targets and appreciate the success they achieve.

How to assess $p$ ? In ways both formal and informal, many clinicians assess a wide range of symptoms that thus give some indication of a client's level of $\mathrm{p}$. They gather extensive 
background information, ask detailed, pointed questions about distress related to the presenting problem, and inquire about other psychiatric symptoms. It may well be that the provision of clinical services would be advanced through the use of validated measures of $p$. There are obvious challenges to representing the wide range of symptoms that reflect $\mathrm{p}$ in a brief, clinical services-friendly measure. The SCL-90 or its 53-item short form, the Brief Symptom Inventory (Derogatis 1975), covers a broad range but may not represent externalizing dysfunction or thought disorder sufficiently.

In considering the best way to measure $\mathrm{p}$, we offer three considerations. The first, as mentioned above, is comprehensiveness, particularly with respect to the inclusion of symptoms of psychosis. We highlight symptoms of psychosis because they are often not included. The second is severity. It is clear that symptoms and dysfunction can vary in their degree of severity (Zimmerman et al., 2018), and it is likely to prove useful to consider severity when developing a new measure of $\mathrm{p}$.

Third, to the degree that a consensus emerges that $\mathrm{p}$ measures impairment, it may make the most sense to develop measures that directly assess functioning or impaired functioning. Validated measures of impairment in functioning, across multiple domains of functioning, may provide particularly useful information for clinicians as well as a clear basis for decisions regarding payment for therapeutic services. Ultimately, the hope is that interventions improve life functioning; in a real sense, symptom alleviation is best understood as a means to that end. Should clinicians document impaired life functioning, the basis for funding treatment is clear. Ro and Clark (2009) addressed the measurement of impaired functioning in interesting ways. Clinicians, clients, and insurance companies would rightfully view scores from standardized 
measures of $\mathrm{p}$, or scores from standardized measures of impaired functioning, with greater confidence than ad hoc measures that vary from clinic to clinic and study to study.

\section{FUTURE DIRECTIONS}

Although in one way it speaks to the validity of the $\mathrm{p}$ concept that $\mathrm{p}$ emerges consistently across studies that use different sets of symptoms/disorders in factor analyses, an important next step is to use the same protocol to measure $\mathrm{p}$ across studies. A common protocol that includes all domains of dysfunction, including thought disorder, will (a) facilitate comparisons across studies, (b) shed further light on symptoms that are more or less central to p, and (c) facilitate the investigation of the substantive meaning of internalizing and externalizing factors with $\mathrm{p}$ removed.

Second, it is important to replicate the finding that p, GFP, and g-PD correlate so highly as to suggest, perhaps even require, a common explanation for the three broad factors (Oltmanns et al., 2018). With respect to $\mathrm{p}$, the impairment hypothesis at present appears to be the only hypothesis fully consistent with existing empirical data. If $\mathrm{p}, \mathrm{GFP}$, and g-PD are so highly correlated they are virtually alternative forms of each other, then variation in impairment or the personality disposition to impairment seem to be the most parsimonious interpretations of g-PD and GFP. Replicating this finding is important because it could pave the way to new investigations of the causal framework for adaptive or maladaptive human functioning. Important avenues for clinical science may be to investigate causes for overall impairment along with causes for specific expressions of impairment.

Related to the above concerns, the high correlation between $\mathrm{p}$, the g-PD, and the GFP speaks directly to (a) the need for continuum models of adaptive/maladaptive functioning and (b) 
the necessity of integrating basic science, such as personality theory, and clinical science. This need for a fuller integration of basic and clinical science becomes clearer when one shifts from the categorical DSM framework for understanding dysfunction to empirically based models that highlight a continuum of functioning. The empirical focus provided by clinical science strongly supports (1) a continuum between adaptive and maladaptive functioning, (2) a common dimension of impairment, and (3) specific expressions of impairment that require clinical attention. As is true in the study of intelligence, there is value in operating at both broad and specific levels.

Third, does measuring $\mathrm{p}$ help clarify prognostic issues and help guide treatment, as we have suggested? Does it facilitate the development of effective treatment plans, clarify treatment goals, create accurate expectations for the funding necessary given likely treatment duration, and relieve distress secondary to one's impairment? Assessing $\mathrm{p}$ in clinical practice may advance the public health. This possibility merits careful empirical investigation. Related to this, can researchers develop a simple, clinician-friendly means of measuring $\mathrm{p}$ ?

Fourth, we consider it a high research priority to investigate the degree to which variability in the stress to which one is exposed and in access to good mental health care influence two things: (1) variability in $\mathrm{p}$ and (2) point estimates of $\mathrm{p}$. Concerning variability in $\mathrm{p}$, low socioeconomic status and non-White status are associated with variable access to quality mental health care and heightened variation in exposure to life stressors. As a result, are estimates of $\mathrm{p}$ more variable for such individuals? Concerning point estimates of $\mathrm{p}$, cultural norms that differ from traditional Western norms can be misconstrued to reflect pathology. To what degree does variation in race-based cultural experiences, gender identity, sexual preference, and other dimensions compromise the accurate assessment of $\mathrm{p}$ ? Is p overestimated in non- 
traditional groups? Is it underestimated in traditional, White, middle and upper class groups? In what ways do these dimensions matter for the development of effective treatments? It is essential for the public health to understand the presence and nature of effects on mental health associated with membership in both traditionally marginalized and traditionally favored groups.

Fifth, it may be useful to develop measures of functioning and impaired functioning, so that clinicians can measure impairment directly, rather than infer high rates of impairment from elevations in many different symptom domains. Ultimately, the target of clinical interventions is to improve life functioning. Valid measures of life functioning that are not dependent on valid measurement of each and every symptom domain will prove useful to clinicians. Perhaps even more important, they will provide a clear basis for decisions to fund psychological interventions.

Recognition of parallel broad factors in the domains of psychopathology, personality, and personality disorders that are stable and predictive of important outcomes represents an important advance in clinical science. Most fundamentally, the further grounding of psychopathology research in empirical methods of defining and describing dysfunction is likely to open up important new avenues of inquiry in the coming years. Advances based on recognizing continua of functioning at the overall level, as well as at the lower level of specific symptoms, promise to clarify understanding of causality and risk, and are likely also to facilitate important advances in treatment. The future of psychopathology research seems brighter than ever before. 


\section{Summary of Key Points:}

1. Empirical approaches to mapping dimensions of psychological dysfunction have consistently observed intercorrelations among the many forms of psychopathology, leading to the identification of a general factor of psychopathology (p).

2. Studies suggest that $\mathrm{p}$ is heritable and stable, and that $\mathrm{p}$ measured in childhood predicts adverse mental health outcomes later in life.

3. $\mathrm{p}$ has been shown to correlate highly with general factors of personality (GFP) and personality disorders (g-PD).

4. Several substantive explanations of $\mathrm{p}$ have been proposed, yet none adequately explain the full spectrum of psychological dysfunction typically included in $\mathrm{p}$.

5. It is most plausible that $\mathrm{p}$ represents an index of nonspecific impairment (secondary to variables loading on $\mathrm{p}$ ) that has the potential to inform the duration and intensity of mental health treatment. 


\section{References}

Abramovitch A, Abramowitz JS, Mittelman A. 2013. The neuropsychology of adult obsessivecompulsive disorder: A meta-analysis. Clin. Psychol. Rev. 338:1163-71.

Achenbach TM. 1966. The classification of children's psychiatric symptoms: A factor-analytic study. Psychol. Monogr. 80(7):1-37.

Alnaes D, Kaufmann T, Doan NT, Córdova-Palomera A, Wang Y, Bettella F, et al. 2018. Association of heritable cognitive ability and psychopathology with white matter properties in children and adolescents. JAMA Psychiat. 75(3):287-95.

American Psychiatric Association. 2013. Diagnostic and statistical manual of mental disorders. 5. Arlington, VA: American Psychiatric Publishing

Arcelus J, Mitchell AJ, Wales J, Nielson S. 2011. Mortality rates in patients with anorexia nervosa and other eating disorders. Arch. Gen. Psychiat. 68(7):724-31.

Bäckström M, Björklund, F., Larsson, MR. 2009. Five-factor inventories have a major general factor related to social desirability which can be reduced by framing items neutrally. $J$. Res. Pers. 43:335-44.

Blinder BJ, Cumella EJ, Sanathara VA. 2006. Psychiatric comorbidities of female inpatients with eating disorders. Psychosom. Med. 68(3):454-62.

Bora E, Yucel M, Pantelis C. 2009. Cognitive endophenotypes of bipolar disorder: a metaanalysis of neuropsychological deficits in euthymic patients and their first-degree relatives. J. Affect. Disorders. 113(1-2):1-20.

Brook JS, Lee JY, Finch SJ, Seltzer N, Brook DW. 2013. Adult work commitment, financial stability, and social environment as related to trajectories of marijuana use beginning in adolescence. Subst. Abus. 34(3):298-305. 
Carver CS, Johnson SL, Joormann J. 2008. Serotonergic function, two-mode models of selfregulation, and vulnerability to depression: What depression has in common with impulsive aggression. Psychol. Bull. 134(6):912-43.

Carver CS, Johnson SL, Joormann J. 2013. Major depressive disorder and impulsive reactivity to emotion: Toward a dual-process view of depression. Brit. J. Clin. Psychol. 52:285-9.

Carver CS, Johnson SL, Timpano KR. 2017. Toward a functional view of the p factor in psychopathology. Clin. Psychol. Sci. 55:880-9.

Caspi A, Houts RM, Belsky DW, Goldman-Mellor SJ, Harrington H, Isreal S, et al. 2014. The p factor: One general psychopathology factor in the structure of psychiatric disorders. Clin. Psychol. Sci. 22:119-37.

Caspi A, Moffitt TE. 2018. All for one and one for all: Mental disorders in one dimension. Am. J. Psychiat. 175:831-44.

Castellanos-Ryan N, Briere FN, O’Leary-Barrett M, Banaschewski T, Bokde A, Bromberg U, et al. 2016. The structure of psychopathology in adolescence and its common personality and cognitive correlates. J. Abnorm. Psychol. 125(8):1039-52.

Chambless DL, Ollendick TH. 2001. Empirically supported psychological interventions: Controversies and evidence. Ann. Rev. Psychol. 52:685-716.

Connelly BS, Ones DS. 2010. Another perspective on personality: Meta-analytic integration of observers' accuracy and predictive validity. Psychol. Bull. 136(6), 1092-1122.

Conway CC, Mansolf M, Reise SP. 2019. Ecological validity of a quantitative classification system for mental illness in treatment-seeking adults. Psychol. Assessment. 31:730-40. 
Copeland WE, Wolke D, Shanahan L, Costello EJ. 2015. Adult functional outcomes of common childhood psychiatric problems: A prospective, longitudinal study. JAMA Psychiat. 72: 892-9.

Cosgrove VE, Rhee SH, Gelhorn HL, Boeldt D, Corley RC, Ehringer MA, et al. 2011. Structure and etiology of co-occurring internalizing and externalizing disorders in adolescents. $J$. Abnorm. Child Psych. 391:109-23.

Costa PT, McCrae RR. 1996. Mood and personality in adulthood. In Handbook of Emotion, Adult Development, and Aging, ed. Magia C, McFadden SH, pp. 369-83. San Diego CA: Academic Press

Cougle JR, Timpano KR, Goetz AR. 2012. Exploring the unique and interactive roles of distress tolerance and negative urgency in obsessions. Pers. Individ. Dif. 52(4):515-20.

Cyders MA, Flory K, Rainer S, Smith GT. 2009. The role of personality dispositions to risky behavior in predicting first-year college drinking. Addiction. 104(2):193-202.

Cyders MA, Smith GT. 2008a. Emotion-based dispositions to rash action: Positive and negative urgency. Psychol. Bull. 134(6):807-28.

Cyders MA, Smith GT. 2008b. Clarifying the role of personality dispositions in risk for increased gambling behavior. Pers. Individ. Dif. 45:503-8

Berg JM, Latzman RD, Bliwise NG, Lilienfeld SO. 2015. Parsing the heterogeneity of impulsivity: A meta-analytic review of the behavioral implications of the UPPS for psychopathology. Psychol. Assessment. 27:1129-46.

Davies SE, Connelly BS, Ones DS, Birkland AS. 2015. The General Factor of Personality: The "Big One," a self-evaluative trait, or a methodological gnat that won't go away? Pers. Individ. Dif. 81:13-22. 
Derogatis LR. 1975. The Symptom Checklist-90-R (SCL-90-R). Minneapolis MN: NCS Assessments

DeYoung CG, Peterson JB, Higgins DM. 2002. Higher-order factors of the Big Five predict conformity: Are there neuroses of health? Pers. Individ. Dif. 33(4):533-52.

Digman JM. 1997. Higher-order factors of the Big Five. J. Pers. Soc. Psychol. 73:1246-56.

Dimidjian S, Hollon S, Dobson K, Schmaling K, Kohlenberg R, Addis M, Jacobson N. 2006. Randomized trial of behavioral activation, cognitive therapy, and antidepressant medication in the acute treatment of adults with major depression. J. Consult. Clin. Psych. 74:658-70.

du Pont A, Rhee SH, Corley RP, Hewitt, JK, Friedman NP. 2018. Rumination and psychopathology: Are anger and depressive rumination differentially associated with internalizing and externalizing psychopathology? Clin. Psychol. Sci. 6:18-31.

Engel SG, Adair CE, Hayas CL, Abraham S. 2009. Health-related quality of life and eating disorders: A review and update. Int. J. Eat. Disorder. 42(2):179-87.

Evans SZ, Simons LG, Simons RL. 2016. Factors that influence trajectories of delinquency throughout adolescence. J. Youth Adolescence. 45(1):156-71.

Fairburn CG, Cooper Z, Doll HA, O'Connor ME, Bohn K, Hawker DM, et al. 2009. Transdiagnostic cognitive-behavioral therapy for patients with eating disorders: a twosite trial with 60-week follow-up. Am. J. Psychiat. 166(3):311-19.

Fergusson DM, Horwood LJ, Ridder EM, Beautrais AL. 2005. Subthreshold depression in adolescence and mental health outcomes in adulthood. Arch. Gen. Psychiat. 62:66-72. 
Fischer S, Smith GT, Cyders MA. 2008. Another look at impulsivity: A meta analytic review of trait impulsivity and its association with bulimic symptoms. Clin. Psychol. Rev. 28:141325.

Flory K, Lynam D, Milich R, Leukefeld C, Clayton R. 2004. Early adolescent through young adult alcohol and marijuana use trajectories: Early predictors, young adult outcomes, and predictive utility. Dev. Psychopathol. 16(1):193-213.

Greene AL, Eaton NR. 2017. The temporal stability of the bifactor model of comorbidity: An examination of moderated continuity pathways. Compr. Psychiat. 72:74-82.

Hasin D, Kilcoyne B. 2012. Comorbidity of psychiatric and substance use disorders in the United States: Current issues and findings from the NESARC. Curr. Opin. Psychiatr. 25: $165-11$.

Health and Human Services. 2001. Mental health: Culture, race, and ethnicity: A supplement to mental health: A report of the Surgeon General. Rockville MD: Substance Abuse and Mental Health Services Administration

Hoptman MJ, Antonius D, Mauro CJ, Parker EM, Javitt DC. 2014. Cortical thinning, functional connectivity, and mood-related impulsivity in schizophrenia: Relations to aggressive attitudes and behavior. Am. J. Psychiat. 171(9):939-48.

Irwing P. 2013. The general factor of personality: Substance or artefact? Pers. Individ. Dif. 55(3): 234-42.

Jahng S, Trull TJ, Wood PK, Tragesser SL, Tomko R, Grant JD, et al. 2011. Distinguishing general and specific personality disorder features and implications for substance dependence comorbidity. J. Abnorm. Psychol. 120(3):656-69. 
John OP, Naumann LP, Soto CJ. 2008. Paradigm shift to the integrative big five trait taxonomy: History, measurement, and conceptual issues. In Handbook of Personality: Theory and Research, ed. John OP, Robins RW, Pervin LA, 3:114-58. New York: Guilford Press

Johnson SL, Carver CS, Joormann J. 2013. Impulsive responses to emotion as a transdiagnostic vulnerability to internalizing and externalizing symptoms. J. Affect. Disord. 150(3):87278.

Keel PK., Baxter MG, Heatherton TF, Joiner TE Jr. 2007. A 20-year longitudinal study of body weight, dieting, and eating disorder symptoms. J. Abnorm. Psychol. 116(2):422-32.

Kessler RC, Chiu WT, Demler O, Merikangas KR, Walters EE. 2005. Prevalence, severity, and comorbidity of twelve-month DSM-IV disorders in the National Comorbidity Survey Replication NCS-R. Arch. Gen. Psychiat. 62:617-627.

Koenen KC, Moffitt TE, Roberts AL, Martin LT, Kubzansky L, Harrington H, et al. 2009. Childhood IQ and adult mental disorders: a test of the cognitive reserve hypothesis. Am. J. Psychiat. 166:50-7.

Kotov R, Waszczuk MA, Krueger RF, Forbes MK, Watson D, Bagby RM, et al. 2017. The hierarchical taxonomy of psychopathology HiTOP: A dimensional alternative to traditional nosologies. J. Abnorm. Psychol. 126(4):454-77.

Krueger RF. 1999. The structure of common mental disorders. Arch. Gen. Psychiat. 56(10):92126.

Krueger RF, Markon KE. 2011. A dimensional-spectrum model of psychopathology: Progress and opportunities. Arch. Gen. Psychiat. 68(1):10-11.

Kupfer DJ, First MB, Regier DA. 2002. A research agenda for DSM-V. Arlington VA: American Psychiatric Association 
Kurtz JE, Tarquini SJ, Iobst EA. 2008. Socially desirable responding in personality assessment: Still more substance than style. Pers. Individ. Dif. 45:22-7.

Laceulle OM, Vollebergh WAM, Ormel J. 2015. The structure of psychopathology in adolescence: Replication of a general psychopathology factor in the TRAILS study. Clin. Psychol. Sci. 3:850-60.

Lahey BB, Krueger RF, Rathouz PJ, Waldman ID, Zald DH. 2017. A hierarchical causal taxonomy of psychopathology across the life span. Psychol. Bull. 143(2):142-86.

Lahey BB. 2009. Public health significance of neuroticism. Am. Psychol. 64:241-56.

Lahey BB, Van Hulle CA, Singh AL, Waldman ID, Rathouz PJ. 2011. Higher-order genetic and environmental structure of prevalent forms of child and adolescent psychopathology. Arch. Gen. Psychiat. 68(2):181-9.

Lahey BB, Applegate B, Hakes JK, Zald DH, Hariri AR, Rathouz PJ. 2012. Is there a general factor of prevalent psychopathology during adulthood? J. Abnorm. Psychol. 121(1):9717.

Lahey BB, Applegate B, Waldman ID, Loft JD, Hankin BL, Rick J. 2004. The structure of child and adolescent psychopathology: Generating new hypotheses. J. Abnorm. Psychol. $113(3): 358-85$.

López SR, Guarnaccia PJ. 2005. Cultural dimensions of psychopathology: The social world's impact on mental illness. In Psychopathology: Foundations for a Contemporary Understanding, ed. Maddux JE, Winstead BA, pp. 19-38. Mahwah NJ: Lawrence Erlbaum Associates

Lynam DR, Widiger TA. 2007. Using a general model of personality to identify the basic elements of psychopathy. J. Pers. Disord. 21(2):160-78. 
Markon KE, Krueger RF, Watson D. 2005. Delineating the structure of normal and abnormal personality: An integrative hierarchical approach. J. Pers. Soc. Psychol. 88:139- 57.

Martel M, Pan PM, Hoffman M, Gadelha A, Rosario M, Mari JJ. 2016. A general psychopathology factor p-factor in children: Structural model analysis and external validation through familial risk and child executive function. J. Abnorm. Psychol. 126(1):137-48.

Mesholam-Gately RI, Giuliano AJ, Goff KP, Faraone SV, Seidman LJ. 2009. Neurocognition in first-episode schizophrenia: A meta-analytic review. Neuropsychology. 23:315-36.

McCrae RR, Costa PT. 1983. Social desirability scales: More substance than style. J. Consult. Clin. Psych. 51(6):882-8.

McElroy E, Belsky J, Carragher N, Fearon P, Patalay P. 2018. Developmental stability of general and specific factors of psychopathology from early childhood to adolescence: dynamic mutualism or p-differentiation? J. Child. Psychol. Psych. 59(6):667-75.

Meijer RR, de Vries RM, van Bruggen V. 2011. An evaluation of the Brief Symptom Inventory18 using item response theory: Which items are most strongly related to psychological distress? Psychol. Assessment. 23(1):193-202.

Mikolajewski AJ, Allan NP, Hart SA, Lonigan CJ, Taylor J. 2013. Negative affect shares genetic and environmental influences with symptoms of childhood internalizing and externalizing disorders. J. Abnorm. Child Psychol. 41:411-23.

Milos GF, Baur V, Muehlebach S, Spindler A. 2013. Axis-I comorbidity is linked to prospective instability of diagnoses within eating disorders. BMC Psychiatry. 13(1):295.

Moleiro, C. 2018. Culture and psychopathology: New perspectives on research, practice, and Clinical training in a globalized world. Front. Psychiatry. 9:366. 
Muhtadie L, Johnson SL, Carver CS, Gotlib IH. 2014. A profile approach to impulsivity in bipolar disorder: The key role of strong emotions. Acta Psychiat. Scand. 129:100-8.

Murray AL, Eisner M, Ribeaud D. 2016. The development of the general factor of psychopathology 'p factor' through childhood and adolescence. J. Abnorm. Child Psychol. 44:1573-86.

Musek, J. 2007. A general factor of personality: Evidence for the Big One in the five-factor model. J Res Pers. 41:1213-33.

Neumann A, Pappa I, Lahey BB, Verhulst FC, Medina-Gomez C, Jaddoe VW. et al. 2016. Single nucleotide polymorphism heritability of a general psychopathology factor in children. J. Am. Acad. Child Psy. 55(12):1038-45.

Oltmanns JR, Smith GT, Oltmanns TF, Widiger TA. 2018. General factors of psychopathology, personality, and personality disorder: Across domain comparisons. Clin. Psychol. Sci. 6(4):581-89.

Ormel J, Oldehinkel AJ, Ferdinand RF, Hartman CA, De Winter AF, Veenstra R, et al. 2005. Internalizing and externalizing problems in adolescence: General and dimension-specific effects of familial loadings and preadolescent temperament traits. Psychol. Med. $35: 1825-35$.

Ozer DJ, Benet-Martinez V. 2006. Personality and the prediction of consequential outcomes. Annu. Rev. Psychol. 57:401-21.

Pearson CM, Wonderlich SA, Smith GT. 2015. A risk and maintenance model for bulimia nervosa: From impulsive action to compulsive behavior. Psychol Rev. 122(3):516-35.

Peterson SJ, Davis HA, Smith GT. 2018. Personality and learning predictors of adolescent alcohol consumption trajectories. J. Abnorm. Psychol. 127(5):482-95. 
Pettersson E, Anckärsater H, Gillberg C, Lichtenstein P. 2013. Different neurodevelopmental symptoms have a common genetic etiology. J. Child. Psychol. Psy. 54(12):1356-65.

Pettersson E, Lahey BB, Larsson H, Lichtenstein P. 2018. Criterion validity and utility of the general factor of psychopathology in childhood: predictive associations with independently measured severe adverse mental health outcomes in adolescence. J. Am. Acad. Child Psy. 57(6):372-83.

Pettersson E, Larsson H, D’Onofrio B, Almqvist C, Lichtenstein, P. 2019. Association of fetal growth with general and specific mental health conditions. JAMA Psychiat. 76(5):536-43.

Pettersson E, Larsson HO, Lichtenstein P. 2016. Common psychiatric disorders share the same genetic origin: A multivariate sibling study of the Swedish population. Mol. Psychiatr. 21:717-21.

Pettersson E, Turkheimer E, Horn EE, Menatti AR. 2012. The general factor of personality and evaluation. Eur. J. Personality. 26(3):292-302.

Revelle W, Wilt J. 2013. The general factor of personality: A general critique. J. Res. Pers. 47:493-504.

Riley EN, Atkinson EA, Smith GT. June 2019. Alcohol consumption as part of the p factor of general psychopathology. Poster presented at the $42^{\text {nd }}$ annual meeting of the Research Society on Alcoholism. Minneapolis MN.

Riley EN, Combs JL, Jordan CE, Smith GT. 2015. Negative urgency and lack of perseverance: Identification of differential pathways of onset and maintenance risk in the longitudinal prediction of nonsuicidal self-injury. Behav. Ther. 46(4):439-48.

Ro E, Clark LA. 2009. Psychosocial functioning in the context of diagnosis: Assessment and theoretical issues. Psychol. Assessment. 21(3):313-24. 
Roberts RE, Fisher PW, Turner JB, Tang M. 2015. Estimating the burden of psychiatric disorders in adolescence: The impact of subthreshold disorders. Soc. Psych. Psych. Epid. 50:397-406.

Roberts BW, Kuncel NR, Shiner R, Caspi A, Goldberg LR. 2007. The power of personality: The comparative validity of personality traits, socioeconomic status, and cognitive ability for Predicting Important Life Outcomes. Perspect. Psychol. Sci. 4:313-45.

Rushton JP, Irwing P. 2011. The general factor of personality. In The Wiley-Blackwell Handbook of Individual Differences, ed. Chamorro-Premuzic T, von Stumm S, Furnham A, pp. 13261. New York, NY: Blackwell Publishing

Sallis H, Szekely E, Neumann A, Jolicoeur-Martineau A, van IJzendoorn M, Hillegers M, et al. 2019. General psychopathology, internalising and externalising in children and functional outcomes in late adolescence. J. Child. Psychol. Psy.

Sauer-Zavala S, Wilner JG, Barlow DH. 2017. Addressing neuroticism in psychological treatment. Personal. Disord. 8(3):191-8.

Selzam S, Coleman JRI, Caspi A, Mofitt TE, Plomin R. 2018. A polygenic $\mathrm{p}$ factor for major psychiatric disorders. Transl. Psychiat. 8(1):205.

Settles RF, Cyders M, Smith GT. 2010. Longitudinal validation of the Acquired Preparedness Model of drinking risk. Psychol. Addict. Behav. 24(2):198-208.

Sharp C, Wright AG, Fowler JC, Frueh BC, Allen JG, Oldham J, et al. 2015. The structure of personality pathology: Both general 'g' and specific 's' factors? J. Abnorm. Psychol. $124(2): 387-98$

Smith GT, Cyders MA. 2016. Integrating affect and impulsivity: The role of positive and negative urgency in substance use risk. Drug Alcohol Depen. 163(Suppl 1): S3-S12. 
Smith GT, Fischer S, Fister SM. 2003. Incremental validity principles of test construction. Psychol. Assessment. 15(4):467-77.

Smith GT, Guller L, Zapolski TC. 2013. A comparison of two models of urgency: Urgency predicts both rash action and depression in youth. Clin. Psychol. Sci. 13:266-75.

Smith GT, McCarthy DM. 1995. Methodological considerations in the refinement of Clinical assessment instruments. Psychol. Assessment. 7:300-8.

Snyder HR, Young JF, Hankin BL. 2017. Strong homotypic continuity in common psychopathology-, internalizing-, and externalizing-specific factors over time in adolescents. Clin. Psychol. Sci. 5(1):98-110.

Spatola CAM, Fagnani C, Pesenti-Gritti P, Ogliari A, Stazi MA, Battaglia M. 2007. A general population twin study of the CBCL/6-18 DSM-oriented scales. J. Am. Acad. Child Psy. 46(5):619-27.

Stochl J, Khandaker GM, Lewis G, Perez J, Goodyer IM, Zammit S, et al. 2015. Mood, anxiety and psychotic phenomena measure a common psychopathological factor. Psychol. Med. 45(7):1483-93.

Strauss ME, Smith GT. 2008. Construct validity: Advances in theory and methodology. Ann. Rev. Clin. Psychol. 5:89-113.

Tackett JL, Lahey BB, Van Hulle C, Waldman I, Krueger RF, Rathouz PJ. 2013. Common genetic influences on negative emotionality and a general psychopathology factor in childhood and adolescence. J. Abnorm. Psychol. 122(4):1142-53.

Ulfvebrand S, Birgegård A, Norring C, Högdahl L, von Hausswolff-Juhlin Y. 2015. Psychiatric comorbidity in women and men with eating disorders results from a large Clinical database. Psychiat. Res. 230(2): 294-99. 
van der Linden D, Dunkel CS, Petrides KV. 2016. The General Factor of Personality GFP as social effectiveness: Review of the literature. Pers. Individ. Dif. 101:98-105.

Waldman ID, Poore HE, van Hulle C, Rathouz PJ, Lahey BB. 2016. External validity of a hierarchical dimensional model of child and adolescent psychopathology: Tests using confirmatory factor analyses and multivariate behavior genetic analyses. J. Abnorm. Psychol. 125(8):1053-66.

Watson D, Clark LA. 1984. Negative affectivity: The disposition to experience aversive emotional states. Psychol. Bull. 96(3):465-90.

Wechsler D. 1944. The measurement of adult intelligence, 3, Baltimore MD: Williams \& Wilkins

Weiss NH, Tull MT, Davis LT, Searcy J, Williams I, Gratz KL. 2015. A preliminary experimental investigation of emotion dysregulation and impulsivity in risky behaviours. Behav. Change. 32(2):127-42.

Whaley AL. 1997. Ethnicity/race, paranoia, and psychiatric diagnoses: Clinician bias versus sociocultural differences. J. Psychopathol. Behav. 19:1-20.

Widiger TA, Oltmanns JR. 2017. The general factor of psychopathology and personality. Clin. Psychol. Sci. 5:182-3.

Widiger TA, Samuel DB. 2005. Diagnostic categories or dimensions? A question for the Diagnostic and statistical manual of mental disorders--fifth edition. J. Abnorm. Psychol. 114(4):494-504.

Widiger TA, Smith GT. 2008. Personality and psychopathology. Handbook of personality: Theory and Res. John OP, Robins RW, Pervin LA, editors. pp. 743-69. New York, NY: The Guilford Press 
Widiger TA, Trull TJ. 2007. Plate tectonics in the classification of personality disorder: Shifting to a dimensional model. Am. Psychol. 62:71-83.

Wright AG, Hopwood CJ, Skodol AE, Morey LC. 2016. Longitudinal validation of general and specific structural features of personality pathology. J. Abnorm. Psychol. 125(8):1120-34.

Wright AG, Krueger RF, Hobbs MJ, Markon KE, Eaton NR, Slade T. 2013. The structure of psychopathology: Toward an expanded quantitative empirical model. J. Abnorm. Psychol 122:281-94.

Wright L, Lipszyc J, Dupuis A, Thayapararajah SW, Schachar R. 2014. Response inhibition and psychopathology: A meta-analysis of go/no-go task performance. J. Abnorm. Psychol. 123:429-39.

Xiang X, Cheng J. 2019. Trajectories of major depression in middle-aged and older adults: A population-based study. Int. J. Geriatr. Psych.

Zapolski TC, Cyders MA, Smith GT. 2009. Positive urgency predicts illegal drug use and risky sexual behavior. Psychol. Addict. Behav. 23(2):348-54.

Zimmerman M, Morgan TA, Stanton K. 2018. The severity of psychiatric disorders. World Psychiatry. 17:258-75.

\section{Reference Annotations:}

\section{Carver CS, Johnson SL, Timpano KR. 2017. Toward a functional view of the p factor in psychopathology. Clin. Psychol. Sci. 55:880-9.}

- A potential substantive explanation for $\mathrm{p}$ which suggests that $\mathrm{p}$ reflects impulsive responsivity to emotion. 
2. Caspi A, Houts RM, Belsky DW, Goldman-Mellor SJ, Harrington H, Isreal S, et al. 2014. The $p$ factor: One general psychopathology factor in the structure of psychiatric disorders. Clin. Psychol. Sci. 22:119-37.

- An early investigation of $\mathrm{p}$, on which many subsequent studies are based.

3. Caspi A, Moffitt TE. 2018. All for one and one for all: Mental disorders in one dimension. Am. J. Psychiat. 175:831-44.

- A review of potential substantive interpretations of $p$, including thought dysfunction and low cognitive functioning.

4. Lahey BB, Applegate B, Hakes JK, Zald DH, Hariri AR, Rathouz PJ. 2012. Is there a general factor of prevalent psychopathology during adulthood? J. Abnorm. Psychol. 121(1):971-7.

- The first investigation of the empirical viability of a general factor of psychopathology.

5. Oltmanns JR, Smith GT, Oltmanns TF, Widiger TA. 2018. General factors of psychopathology, personality, and personality disorder: Across domain comparisons. Clin. Psychol. Sci. 6(4):581-89.

- An investigation of the relationship between $\mathrm{p}$ and general factors of personality and personality disorders .

6. Pettersson E, Lahey BB, Larsson H, Lichtenstein P. 2018. Criterion validity and utility of the general factor of psychopathology in childhood: predictive associations with 
independently measured severe adverse mental health outcomes in adolescence. $\mathrm{J} . \mathrm{Am}$. Acad. Child Psy. 57(6):372-83.

- An investigation of adverse mental health outcomes associated with high levels of $\mathrm{p}$ in childhood.

7. Tackett JL, Lahey BB, Van Hulle C, Waldman I, Krueger RF, Rathouz PJ. 2013. Common genetic influences on negative emotionality and a general psychopathology factor in childhood and adolescence. J. Abnorm. Psychol. 122(4):1142-53.

- A potential substantive explanation of $p$ which suggests that $p$ reflects negative emotionality. 


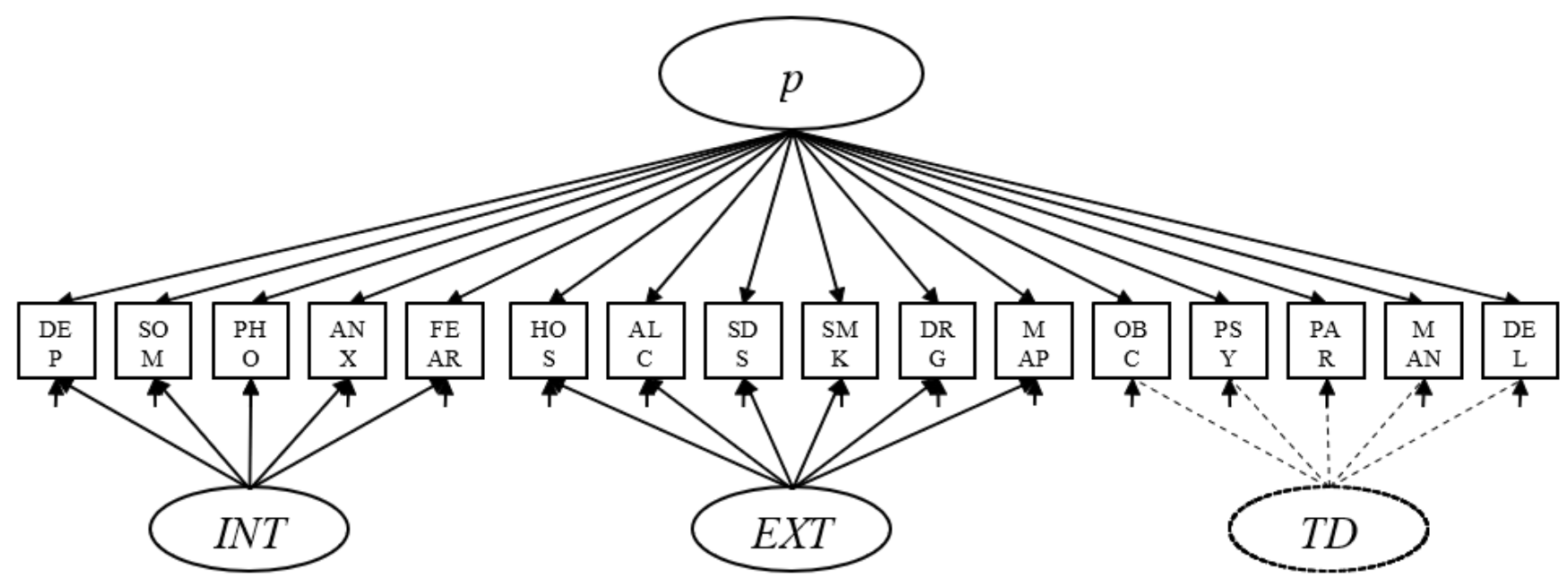

Figure 1. Bifactor model of the $p$-factor, using indicators from Oltmanns et al. (2018). INT = internalizing, EXT = externalizing, TD = thought disorder. TD in dashed lines because thought disorder indicators often load only on $p$-factor in bifactor models. DEP = depression, SOM = somatic complaints, $\mathrm{PHO}=$ phobias, $\mathrm{ANX}=$ anxiety, FEAR $=$ fears, $\mathrm{HOS}=$ hostility, $\mathrm{ALC}=$ alcohol problems, $\mathrm{SDS}=$ substance dependence, $\mathrm{DRG}=$ drug abuse, $\mathrm{MAP}=$ antisocial personality features, $\mathrm{OBC}=$ obsessive-compulsive behavior, $\mathrm{PSY}=$ psychoticism, $\mathrm{PAR}=$ paranoia, $\mathrm{MAN}=$ mania, $\mathrm{DEL}=$ delusions.

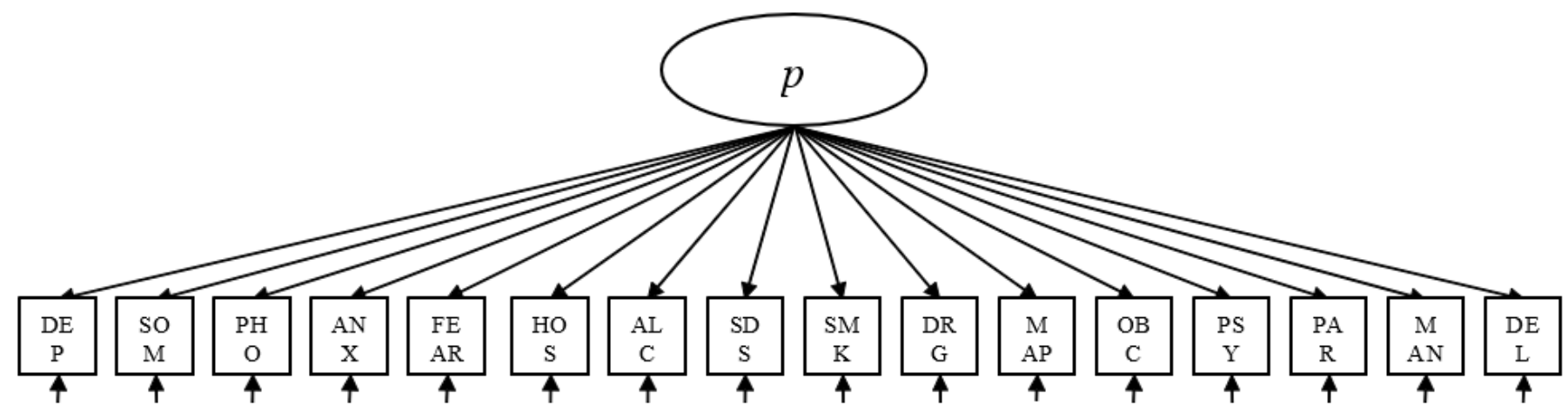

Figure 2. Single-factor model of the p-factor, using indicators from Oltmanns et al. (2018). DEP $=$ depression, $\mathrm{SOM}=$ somatic complaints, $\mathrm{PHO}=$ phobias, $\mathrm{ANX}=$ anxiety, FEAR = fears, HOS $=$ hostility, $\mathrm{ALC}=$ alcohol problems, $\mathrm{SDS}=$ substance dependence, $\mathrm{DRG}=$ drug abuse, $\mathrm{MAP}=$ antisocial personality features, $\mathrm{OBC}=$ obsessive-compulsive behavior, $\mathrm{PSY}=$ psychoticism, $\mathrm{PAR}=$ paranoia, $\mathrm{MAN}=$ mania, $\mathrm{DEL}=$ delusions. 


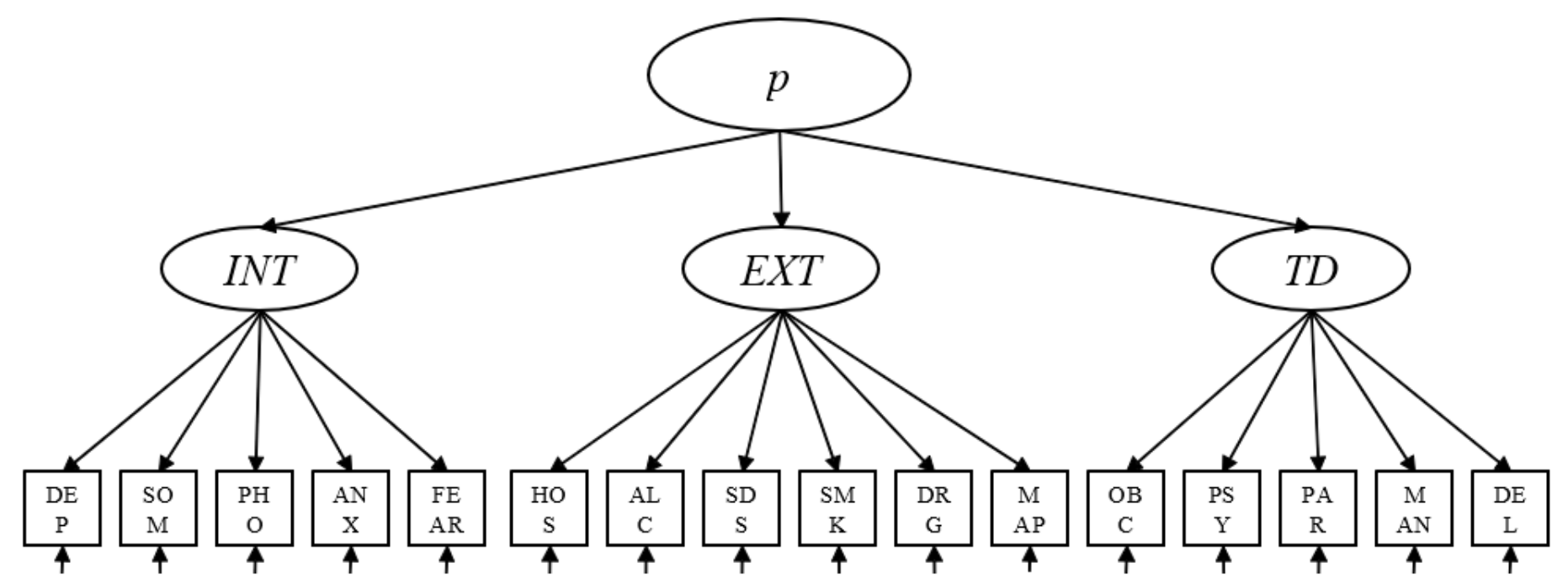

Figure 3. Higher-order model of the $p$-factor, using indicators from Oltmanns et al. (2018). INT = internalizing, $\mathrm{EXT}=$ externalizing, $\mathrm{TD}=$ thought disorder. $\mathrm{DEP}=$ depression, $\mathrm{SOM}=$ somatic complaints, $\mathrm{PHO}=$ phobias, $\mathrm{ANX}=$ anxiety, FEAR $=$ fears, $\mathrm{HOS}=$ hostility, $\mathrm{ALC}=$ alcohol problems, $\mathrm{SDS}=$ substance dependence, $\mathrm{DRG}=$ drug abuse, $\mathrm{MAP}=$ antisocial personality features, $\mathrm{OBC}=$ obsessive-compulsive behavior, $\mathrm{PSY}=$ psychoticism, $\mathrm{PAR}=$ paranoia, $\mathrm{MAN}=$ mania, DEL = delusion. 